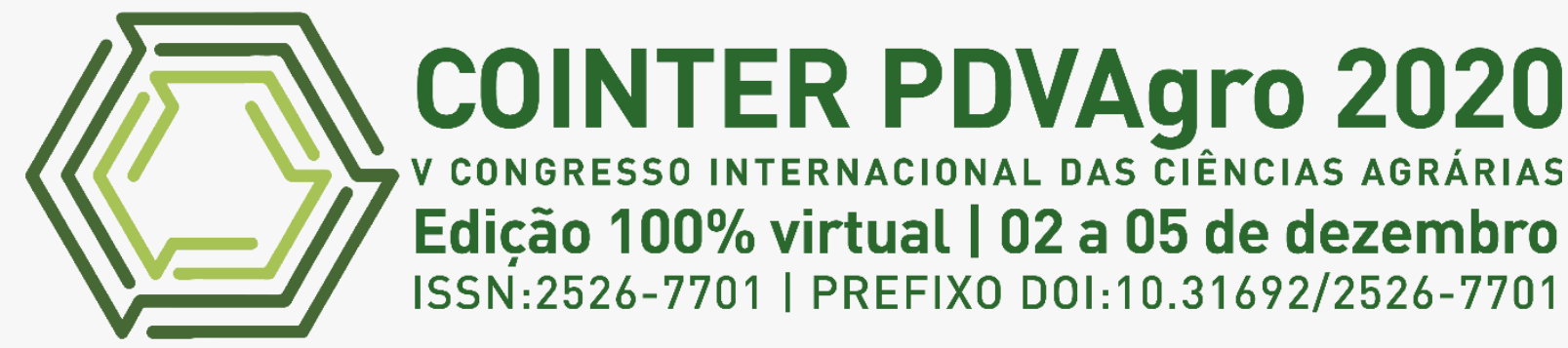

\title{
CARACTERÍSTICAS ESTRUTURAIS E PRODUTIVAS DO CV. BRS TAMANI MANEJADA SOB ADUBAÇÃO NITROGENADA
}

\author{
CARACTERÍSTICAS ESTRUCTURALES Y PRODUCTIVAS DEL CV. BRS \\ TAMANI MANIPULADO BAJO FERTILIZACIÓN CON NITRÓGENO
}

\section{STRUCTURAL AND PRODUCTIVE CHARACTERISTICS OF THE CV. BRS TAMANI HANDLED UNDER NITROGEN FERTILIZATION}

\author{
Apresentação: Comunicação Oral \\ Milena Alves dos Santos'; José Lucas Guedes dos Santos²; Jéssica Sousa Maranguape ${ }^{3}$; Elayne Cristina Gadelha \\ Vasconcelos ${ }^{4}$; Magno José Duarte Cândido ${ }^{5}$
}

DOI : $\underline{\text { https://doi.org/10.31692/2526-7701.VCOINTERPDVAgro.0431 }}$

\begin{abstract}
RESUMO
No cenário cada vez mais competitivo da pecuária, faz-se necessário a adoção de tecnologias mais eficientes no que diz respeito a adubação, tecnologias essas, que otimizem a produtividade e garantam à sustentabilidade ambiental. Nesse contexto, objetiva-se com o presente trabalho, Nesse contexto, objetiva-se com o presente trabalho, avaliar as características estruturais e produtivas do capim Megathyrsus maximus cv. BRS Tamani manejado sob diferentes parcelamentos de um adubo nitrogenado comercial de liberação controlada. O experimento foi conduzido no Núcleo de Ensino e Estudos em Forragicultura -NEEF, pertencente à Universidade Federal do Ceará. A área experimental foi alocada em aproximadamente $300 \mathrm{~m}^{2}$, sendo subdividida em 24 parcelas de $12,5 \mathrm{~m}^{2}$ cada. Utilizouse um delineamento em blocos casualizados com seis tratamentos e quatro repetições. Os tratamentos consistiram em diferentes parcelamentos de ureia de liberação controlada $(1 ; 2 ; 4$ e 6 aplicações por ano respectivamente), de ureia convencional e o tratamento controle (sem adubação nitrogenada). Foram avaliadas as seguintes variáveis estruturais: altura do dossel (AD) e densidade populacional de perfilhos (DPP). No que diz respeito aos componentes da biomassa, avaliou-se as biomassas de forragem total colhível (BFTc), forragem verde colhível $\left(\mathrm{BFV}_{\mathrm{C}}\right)$, lâmina foliar verde colhível $\left(\mathrm{BLV}_{\mathrm{C}}\right)$, colmo verde colhível $\left(\mathrm{BCV}_{\mathrm{C}}\right)$ e forragem morta colhível $\left(\mathrm{BFM}_{\mathrm{C}}\right)$. Não foi constatado efeito para as variáveis $\mathrm{AD}$, DPP, BFMc e BCVc . As BFTc, $\mathrm{BFV}_{\mathrm{C}}$ e a $\mathrm{BLV}_{\mathrm{C}}$ foram em média, 40,78\%, 31,32\% e 33,40\% maiores nos pastos manejados com adubo nitrogenado comercial de liberação controlada, com destaque para o parcelamento de 6 vezes. A aplicação do adubo nitrogenado comercial de liberação controlada não influenciou as características estruturais da pastagem de Megathyrsus maximus cv. Tamani. Os tratamentos com adubo nitrogenado comercial de liberação controlada, independentemente do

\footnotetext{
${ }^{1}$ Mestranda em Zootecnia, Universidade Federal do Ceará, milenaalvessanto@ outlook.com

${ }^{2}$ Mestrando em Zootecnia, Universidade Federal do Ceará, lucas2011guedes@ hotmail.com

${ }^{3}$ Doutoranda em Zootecnia, Universidade Federal do Ceará, jessicamaranguape@ hotmail.com

${ }^{4}$ Doutora em Zootecnia, Bolsista de Desenvolvimento Cientifico Regional do CNPq, Instituto Federal do Piauí Campus Cocal, elaynegadelha@gmail.com

${ }^{5}$ Doutor em Zootecnia, Prof. do Departamento de Zootecnia, Universidade Federal do Ceará, magno@ufc.br
} 
parcelamento adotado, proporcionaram maior produtividade da gramínea BRS Tamani durante o período avaliado.

Palavras-Chave: Ureia de liberação controlada, Megathyrsus maximus, biomassa de forragem, densidade populacional de perfilhos.

\title{
RESUMEN
}

En el escenario cada vez más competitivo de la ganadería, es necesario adoptar tecnologías más eficientes en materia de fertilización, tecnologías que optimicen la productividad y garanticen la sostenibilidad ambiental. En este contexto, apuntamos con el presente trabajo, En este contexto, apuntamos con el presente trabajo, evaluar las características estructurales y productivas de Megathyrsus maximus cv. BRS Tamani se gestionó bajo diferentes entregas de un fertilizante nitrogenado comercial de liberación controlada. El experimento se realizó en el Centro de Docencia y Estudios en Forrajes NEEF, perteneciente a la Universidad Federal de Ceará. El área experimental se asignó aproximadamente a $300 \mathrm{~m}^{2}$, subdividiéndose en 24 parcelas de $12,5 \mathrm{~m}^{2}$ cada una. Se utilizó un diseño de bloques al azar con seis tratamientos y cuatro repeticiones. Los tratamientos consistieron en diferentes entregas de urea de liberación controlada $(1,2,4$ y 6 aplicaciones por año respectivamente), urea convencional y el tratamiento control (sin fertilización nitrogenada). Se evaluaron las siguientes variables estructurales: altura del dosel (AD) y densidad de población de macollos (DPP). Con respecto a los componentes de la biomasa, se evaluaron las biomasas de forraje cosechable total (BFTc), forraje cosechable verde (BFVC), cosechable de hoja verde (BLVC), tallo cosechable verde (BCVC) y forraje muerto cosechable (BFMC). No hubo efecto para las variables AD, DPP, BFMc y BCVc. BFTc, BFVC y BLVC fueron, en promedio, 40,78\%, 31,32\% y 33,40\% más altos en pasturas manejadas con fertilizante nitrogenado comercial de liberación controlada, con énfasis en la 6 veces. La aplicación de fertilizantes nitrogenados comerciales de liberación controlada no influyó en las características estructurales de Megathyrsus maximus cv. Tamani. Los tratamientos con fertilizante nitrogenado comercial de liberación controlada, independientemente del abono adoptado, proporcionaron una mayor productividad del pasto BRS Tamani durante el período evaluado.

Palabras Clave: Urea de liberación controlada, Megathyrsus maximus, biomasa de forrajes, densidad de población de macollos.

\begin{abstract}
In the increasingly competitive scenario of livestock, it is necessary to adopt more efficient technologies with regard to fertilization, technologies that optimize productivity and guarantee environmental sustainability. In this context, we aim with the present work, In this context, we aim with the present work, to evaluate the structural and productive characteristics of Megathyrsus maximus cv. BRS Tamani managed under different installments of a controlled release commercial nitrogen fertilizer. The experiment was conducted at the Center for Teaching and Studies in Forage -NEEF, belonging to the Federal University of Ceará. The experimental area was allocated approximately $300 \mathrm{~m}^{2}$, being subdivided into 24 plots of $12.5 \mathrm{~m}^{2}$ each. A randomized block design with six treatments and four replications was used. The treatments consisted of different installments of controlled-release urea (1, 2, 4 and 6 applications per year respectively), conventional urea and the control treatment (without nitrogen fertilization). The following structural variables were evaluated: canopy height (AD) and tiller population density (DPP). With regard to biomass components, biomasses of total harvestable forage $(\mathrm{BFTc})$, green harvestable forage (BFVC), green leaf harvestable (BLVC), green harvestable stem $(B C V C)$ and harvestable dead forage (BFMC) were evaluated. There was no effect for the variables $\mathrm{AD}$, DPP, BFMc and BCVc. BFTc, BFVC and BLVC were, on average, $40.78 \%, 31.32 \%$ and $33.40 \%$ higher in pastures managed with controlled release commercial nitrogen fertilizer, with emphasis on the 6-fold installment. The application of controlled release commercial nitrogen fertilizer did not influence the structural characteristics of Megathyrsus maximus cv. Tamani. The treatments with commercial nitrogen fertilizer of controlled release, regardless of the installment adopted, provided greater productivity of the grass BRS Tamani during the evaluated period.
\end{abstract}

Keywords: Controlled-release urea, Megathyrsus maximus, forage biomass, tiller population density.

\section{INTRODUÇÃO}


Na maioria dos estados do nordeste brasileiro, a produtividade das pastagens é baixa, o que pode estar relacionado à distribuição irregular de chuvas ao longo do ano, além da baixa disponibilidade de tecnologias específicas para a produção animal nessa região. Além desta questão, são poucas as opções de forrageiras adaptadas a região, havendo assim, necessidade de investigações acerca desta carcaterística nos cultivares disponíveis no mercado (MARTUSCELLO et al., 2015), como por exemplo, a cv. Tamani, pertencente a espécie Megathyrsus maximus.

A produção de biomassa de uma pastagem pode ser otimizada pela utilização de de fertilizantes, principalmente os nitrogenados (ALEXANDRINO et al., 2004; SILVA et al., 2009), constituindo assim, uma prática desejável para o aumento da produção e consequentemente a maximização uso das pastagens (ANDRADE et al., 2000).

A literatura retrata que praticamente todo nitrogênio é aplicado por meio de fertilizantes solúveis em água, como ureia, sulfato de amônio ou fosfato de diamônio (EDMEADES, 2015), contudo, apesar da importância da utilização de tecnologias como a adubação para a elevação da produtividade das pastagens, o uso indiscriminado de fertilizantes nitrogenados, além de elevar o custo de produção, pode causar danos ao ambiente (SANTOS, 2004).

Edmeades (2015) explica que o $\mathrm{N}$ nesses produtos está sujeito a perdas para o meio ambiente por meio de: volatilização $\left(\mathrm{NH}_{3}\right)$, desnitrificação (gases de nitrogênio e óxidos nitrosos), lixiviação $\left(\mathrm{NO}_{3}^{-}\right)$e escoamento $\left(\mathrm{NH}_{3}\right.$ e $\left.\mathrm{NO}_{3}^{-}\right)$. No que diz respeito as perdas, acredita- se que a volatilização é um dos principais problemas relacionados ao uso da ureia, sendo esse processo potencializado por condições relacionadas a falta de precipitação acompanhada de altas temperaturas após a adubação nitrogenada (MARTHA-JUNIOR et al., 2004).

Diante dessa problemática de danos ambientais, aliada à baixa eficiência na utilização do nitrogênio (LAM et al., 2019), estudos sobre medidas de mitigação da amônia vem sendo realizados, incluindo em tais medidas, por exemplo, o uso de fertilizantes de eficiência aprimorada, como grânulos de ureia revestidos com um inibidor de urease, e fertilizantes de liberação controlada, comprovadamente eficazes quando usados em vários sistemas agrícolas (PAN et al., 2016; XIA et al., 2017) além de práticas estratégias de manejo, como o parcelamento da adubação.

Neste sentido, objetiva-se com o presente trabalho, avaliar as características estruturais e produtivas do capim Megathyrsus maximus cv. Tamani manejado sob parcelamentos de um adubo nitrogenado comercial de liberação controlada. 


\section{FUNDAMENTAÇÃO TEÓRICA}

\section{Adubação nitrogenada}

O nitrogênio é considerado elemento essencial para as plantas, estando presente na composição das mais importantes biomoléculas, como ATP, NADH, NADPH, clorofila, proteínas e inúmeras enzimas (MIFLIN \& LEA, 1976; HARPER, 1994). Em sistemas de produção a pasto, a disponibilidade de nitrogênio na maioria das vezes, é um fator limitante, por influenciar no crescimento e desenvolvimento das plantas, quando comparado com os outros nutrientes (BREDEMEIR, 2000).

A ureia é a fonte nitrogenada mais utilizada no Brasil, principalmente por se tratar de um fertilizante bastante acessível economicamente. Quando aplicada ao solo, a ureia pode sofrer hidrólise por ação da enzima urease, convertendo o $\mathrm{R}^{-\mathrm{NH}_{2}}$ para $\mathrm{NH}_{4}{ }^{+}$, então por consumir $\mathrm{H}^{+}$do meio, essa reação promove elevação no $\mathrm{pH}$ do solo próximo aos grânulos de fertilizantes, favorecendo a transformação do $\mathrm{NH}_{4}{ }^{+}$para $\mathrm{NH}_{3}$, sendo esta uma forma gasosa e passível de perdas por volatilização (KIEHL, 1989).

Por isso torna-se importante estudar novas tecnologias que permitam reduzir essas perdas por volatilização, garantindo um melhor aproveitamento por parte da planta. Nesse contexto, alguns estudos vem sendo realizados com a tecnologia de adubos de liberação controlada, podendo este ser definido como aqueles nos quais são conhecidos os fatores que determinam a quantidade, o padrão e a duração da liberação do nutriente para as plantas (VILLALBA, 2014).

Os adubos de liberação controlada oferecem maior controle sobre a duração, o padrão, e a taxa de liberação de nutrientes, o que permite maior eficiência e minimiza os impactos ambientais (SHAVIV, 2005). Além disso, quando comparado a outros fertilizantes, esses adubos são menos sensíveis a fatores ambientais e de solo (VILLALBA, 2014).

Quando se pensa em "eficiência da adubação nitrogenada', o foco é a sincronia entre a disponibilidade de nitrogênio no solo e a demanda do nutriente pelas plantas, principalmente nos estádios mais críticos (CREWS; PEOPLE, 2005). Uma das alternativas para melhorar essa eficiência e ao mesmo tempo diminuir possíveis impactos ambientais é a utilização dos fertilizantes de liberação controlada.

\section{Manejo da adubação}

Especial atenção deve ser dada ao manejo da fertilidade do solo. Dentre os 
macronutrientes, o nitrogênio é o que participa em maior quantidade dos processos de crescimento vegetal. Além dele, o fósforo e o potássio também participam em grande quantidade no metabolismo das plantas. Assim, quando se busca melhorar a fertilidade de um solo, deve-se atentar ao fornecimento desses três nutrientes, principalmente o nitrogênio. $\mathrm{O}$ manejo deste nutriente em particular também deve considerar a sua grande mobilidade no solo, o que requer reposição constante pelo emprego de aplicações escalonadas. Estudos da aplicação de doses de nitrogênio sobre o rendimento de forragem são inúmeros. $\mathrm{O}$ aumento no rendimento deve-se ao estímulo ao crescimento e alteração na partição de carbono em prol da parte aérea (MARSCHNER, 1995). Para a adubação de manutenção, doses menores que $50 \mathrm{~kg} / \mathrm{ha}$ de nitrogênio são consideradas inócuas, embora esta dose seja recomendável para sistemas extensivos, devendo ser aplicada no início do período de chuvas.

Para maximizar a conversão do nutriente aplicado em biomassa, é preciso satisfazer a exigência nutricional da planta, atendendo os macros e micronutrientes em todos os estádios de crescimento/desenvolvimento, visando-se otimizar a produção. É importante lembrar que cada planta forrageira apresenta exigência nutricional específica que garantirá maior conversão em biomassa de forragem, desde que não ocorra qualquer desordem nutricional, por deficiência ou por excesso (PRADO, 2008). Em pastagens tropicais manejadas intensivamente, a adubação nitrogenada é fundamental para se maximizar a biomassa de forragem, pois esse nutriente naturalmente disponível não é suficiente para atender à demanda requerida pelas forrageiras de alta produção (KLUTHCOUSKI; AIDAR, 2003).

\section{Importância da estrutura da pastagem para a produção animal}

As plantas passam por fases ao longo do tempo, caracterizadas por investimentos em estruturas. Em cada fase da vida da planta, esta apresenta diferentes proporções de folhas, colmos, inflorescência e material morto no perfil do dossel, significando que a composição da estrutura das plantas se altera ao longo do tempo (CARVALHO et al., 2001).

Pode-se definir a estrutura do dossel forrageiro como a distribuição e o arranjo da parte aérea das plantas, ou a quantidade e organização de seus componentes, dentro de sua comunidade, sobre o solo (LACA \& LEMAIRE, 2000). Assim, estudar os componentes estruturais da pastagem é fundamental, pois afeta não só o crescimento e a competição entre plantas (LEMAIRE, 2001), como também o comportamento e o desempenho dos animais em pastejo (CARVALHO et al., 2001).

Os componentes estruturais da pastagem: tamanho da folha, relação folha/colmo, 


\section{CARACTERÍSTICAS ESTRUTURAIS E PRODUTIVAS}

densidade populacional de perfilhos e o número de folhas por perfilhos, aliados às características morfogênicas (alongamento de folhas e hastes, aparecimento e duração de vida das folhas), às variáveis ambientais (luz, temperatura, água e nutrientes) e ao manejo adotado determinam a produtividade e a perenidade das pastagens (CÂNDIDO, 2003).

\section{Componentes estruturais da pastagem}

A altura do dossel (AD) é uma variável de fácil mensuração e consiste numa primeira aproximação da quantidade de forragem presente numa determinada área. Segundo Hodgson (1990), a altura do dossel é uma das medidas que fornece melhor indicação da produção de forragem e desempenho do animal em circunstâncias particulares, e padrões mais consistentes de respostas sob diferentes condições. Assim, a altura é uma ferramenta de avaliação fácil de mensurar, constituindo-se um parâmetro satisfatório para avaliação do manejo de pastagens.

Já Stobbs (1973) afirmou que no caso dos pastos tropicais, ocorre uma diminuição da densidade de forragem com a elevação da altura, não havendo, portanto uma relação direta entre altura e massa de forragem. Assim, para gramíneas do tipo $\mathrm{C}_{4}$, a altura do pasto pode comprometer o valor nutritivo da forragem em virtude do alongamento do pseudocolmo, o que aumenta a fração de carboidratos estruturais, o que leva a uma diminuição do teor de proteína bruta e do consumo em virtude da redução na ingestão de matéria seca (MS).

A biomassa de forragem verde (BFV) é uma característica estrutural que prediz a produção da fração verde da biomassa total da pastagem (folhas e colmos) em determinado espaço, e pode ser estimada pela diferença entre a massa seca de forragem total e a massa seca de forragem morta. Todavia, esta variável não é precisa no que diz respeito à qualidade do pasto, visto que a fração colmo aumenta ao longo do tempo, o que pode reduzir a qualidade do pasto. Segundo Minson (1990) quando a biomassa de forragem verde está abaixo de $2.000 \mathrm{~kg}$. $\mathrm{ha}^{-1}$, ocorre redução na ingestão de MS, principalmente devido a uma diminuição do tamanho de bocados e, conseqüentemente, aumento no tempo de pastejo.

A biomassa de lâmina foliar verde (BLV) é uma das variáveis estruturais mais importantes no que diz respeito à qualidade da pastagem, sendo determinada através da fração folha da biomassa total colhida em determinado espaço.

A BLV pode ser estimada pela diferença entre a biomassa de forragem verde e biomassa de colmo verde. Por meio dessa variável, pode-se estimar a produção de folhas na condição residual e pré-pastejo do pasto, permitindo estimar a área foliar verde remanescente após o pastejo e a disponibilidade de forragem no pré-pastejo, sendo estas características importantes para o manejo da pastagem. 
A biomassa de colmo verde (BCV), embora não significativa no início da rebrotação do pasto, pode se tornar expressiva a partir do momento em que o processo de alongamento do colmo se intensifica. Assim, a partir de certa idade de rebrotação, a biomassa de colmos passará a representar grande proporção da BFV, contribuindo para o acúmulo de biomassa verde na pastagem, porém com pouco ou nenhum benefício para o animal em pastejo, devido à redução na relação folha/colmo e à maior dificuldade de manipulação da forragem pelo animal em pastejo (CÂNDIDO, 2003).

A densidade populacional de perfilhos (DPP) é uma variável estrutural que resulta do equilíbrio entre a taxa de surgimento e mortalidade dos perfilhos. Entretanto, esse equilíbrio entre a taxa de surgimento e a taxa de mortalidade dos perfilhos é altamente dependente do regime de desfolhação, o qual por sua vez determina a evolução do IAF (LEMAIRE ;CHAPMAN, 1996). Assim, a taxa de surgimento potencial de perfilhos só pode ser atingida quando o IAF da pastagem é baixo (NABINGER; PONTES, 2001), devido ao fato do surgimento de novos perfilhos decrescer à medida que ocorre o crescimento no IAF.

\section{METODOLOGIA}

O experimento foi realizado no Núcleo de Ensino e Estudos em Forragicultura NEEF/DZ/CCA/UFC, pertencente à Universidade Federal do Ceará. Os dados utilizados no presente estudo são preliminares e foram coletados no período de março a abril de 2020, durante a época chuvosa.

A cidade de Fortaleza, localiza-se na zona litorânea a 15,49 m, com latitude sul 034' $47^{\prime}$ ' e longitude oeste $38^{\circ} 31^{\prime} 23^{\prime}$ '. O clima da região é Aw', classificação dada por Köppen (1923), que se configura como tropical chuvoso com precipitações de verão. As médias anuais de temperatura do ar, pluviometria, evapotranspiração potencial e umidade relativa são respectivamente: $26,3{ }^{\circ} \mathrm{C} ; 1600 \mathrm{~mm} ; 3215 \mathrm{~mm} ; 62 \%$. O solo é classificado como Argissolo Amarelo Eutrófico Típico (EMBRAPA, 2006). A área experimental foi alocada em aproximadamente $300 \mathrm{~m}^{2}$, em uma área implementada há dois anos com cv. BRS Tamani, sendo subdividida em 24 parcelas de 12,5 $\mathrm{m}^{2}$ cada (Figura 01). 


\section{CARACTERÍSTICAS ESTRUTURAIS E PRODUTIVAS}

Figura 01: Vista geral da área experimental

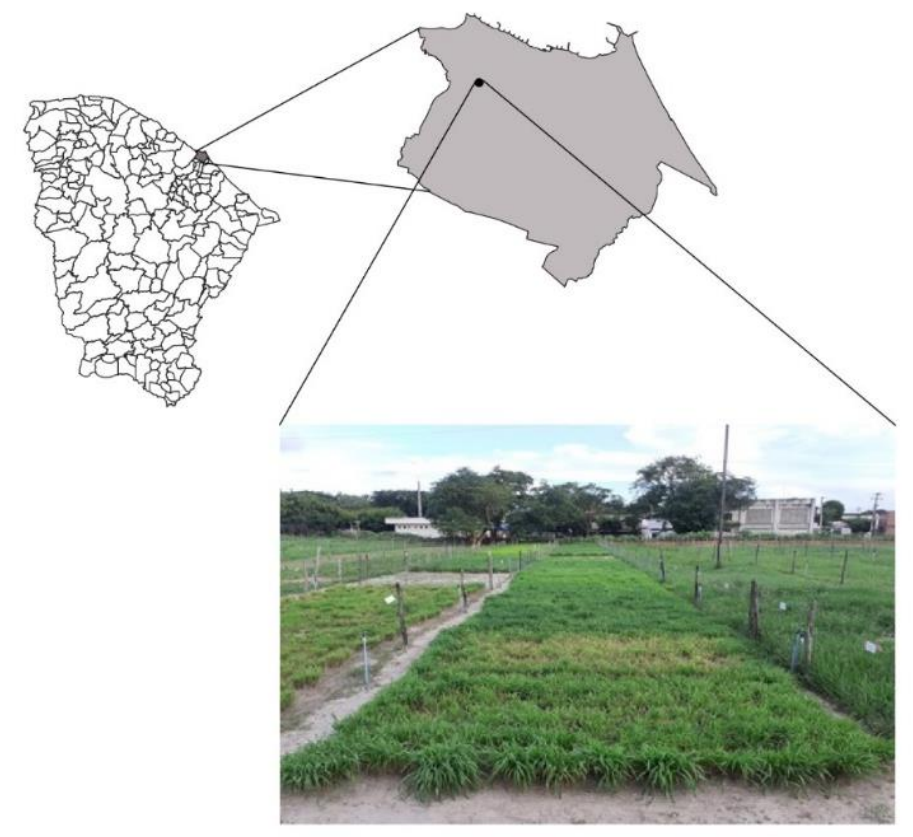

Fonte: IBGE, malha municipal, 2019 e Própria (2020)

Os dados climáticos do período experimental foram obtidos pelo Instituto Nacional de Meteorologia - INMET (2020) e estão apresentados na Figura 02.

Figura 02: Médias da temperatura do ar, umidade relativa do ar e precipitação durante o periodo experimental

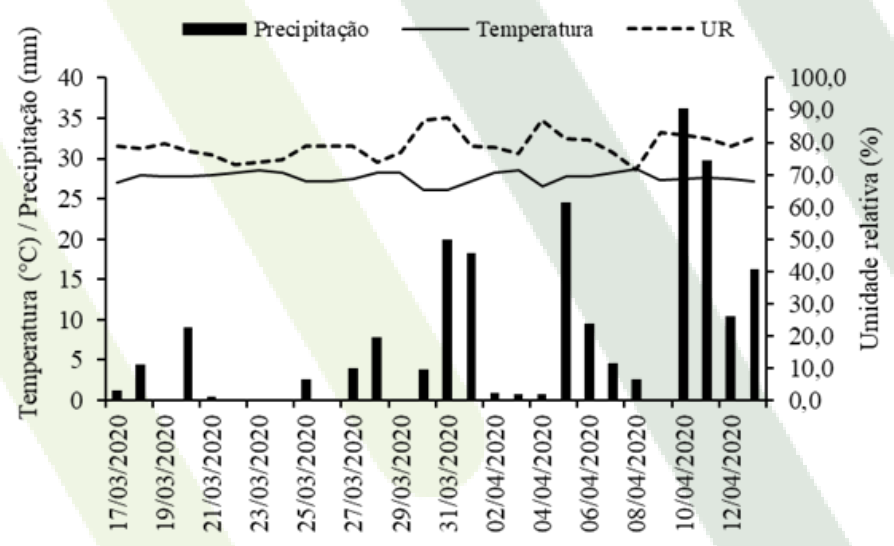

Fonte: INMET (2020)

Antes do inicio do experimento coletaram-se amostras de solo, na camada de $0-20 \mathrm{~cm}$ de profundidade, feito uma amostra composta e levada ao Laboratorio de Solos da Universidade Federal do Ceará para a determinação das características químicas (Tabela 01). A partir dos resultados da análise de solo, foi feita a recomendação de adubação para o capim com alto potencial produtivo e manejo de alto nível tecnológico (CFSEMG, 1999), com aplicações de manutenção/produção durante os ciclos de crescimento da forrageira durante o período 
experimental.

Tabela 01: Características químicas do solo da área experimental, na profundidade de 0 a $20 \mathrm{~cm}$

\begin{tabular}{|c|c|c|c|c|c|c|c|c|}
\hline $\begin{array}{c}\mathbf{p H} \\
\left(\mathrm{H}_{2} \mathrm{O}\right) \\
\end{array}$ & $\begin{array}{c}\text { MO } \\
\mathrm{g} \mathrm{dm}^{-3}\end{array}$ & $\begin{array}{c}\mathbf{P} \\
-----\mathrm{m} \\
\end{array}$ & $\begin{array}{c}\mathbf{K}^{+} \\
n^{-3}----- \\
\end{array}$ & $\begin{array}{r}\mathrm{Ca}^{2+} \\
--- \\
\end{array}$ & $\mathrm{Mg}^{2+}$ & $\begin{array}{c}\mathbf{A l}^{\mathbf{3 +}} \\
\mathrm{mol}_{\mathrm{c}} \mathrm{dn}\end{array}$ & SB & CTCt \\
\hline 6,8 & 7,5 & 21,0 & 70,4 & 1,1 & 0,3 & 0 & 1,9 & 2,4 \\
\hline Acidez fraca & Baixa & Médio & Médio & Baixo & Baixo & Baixo & Médio & Baixa \\
\hline
\end{tabular}

Fonte: (Própria, 2020)

Adotou-se um delineamento em blocos casualizados com seis tratamentos e quatro repetições, totalizando 24 unidades experimentais. Os tratamentos consistiram de diferentes parcelamentos de ureia de liberação controlada (a cada 365 dias; a cada 182 dias; a cada 91 dias e a cada 61 dias, correspondendo a 1; 2; 4 e 6 aplicações por ano respecticamente), de ureia convencional e o tratamento controle (sem adubação nitrogenada). A dose de nitrogênio utilizada no presente estudo foi equivalente a $600 \mathrm{~kg} \mathrm{ha}^{-1}$. A ureia de liberação controlada utilizada, nome comercial Polyblen, foi desenvolvida pela Produquímica Indústria e Comércio S.A.

O corte de uniformização foi realizado a $10 \mathrm{~cm}$ de altura com o auxílio de uma roçadeira lateral (Figura 03 A e B). Em seguida foi feita a adubação de manutenção, segundo recomendações baseando-se na análise do solo, nas seguintes doses: $20 \mathrm{~kg} \mathrm{ha}^{-1}$ de $\mathrm{P}_{2} \mathrm{O}_{5}$, tendo como fonte o superfosfato simples, $100 \mathrm{~kg} \mathrm{ha}^{-1}$ de $\mathrm{K}_{2} \mathrm{O}$, usando-se o cloreto de potássio como fonte e $50 \mathrm{~kg} \mathrm{ha}^{-1}$ de FTE BR 12 como fonte de micronutrientes. A adubação com nitrogênio foi feita de acordo com os tratamentos preconizados. A dispersão dos fertilizantes foi feita a lanço (Figura $03 \mathrm{C}$ ).

Após novo crescimento, quando o dossel atingiu uma condição pré-desfolhação de $95 \%$ de interceptação da radiação fotossinteticamente ativa (IRFA), foram realizadas avaliações estruturais do dossel e as coletas das biomassas colhiveis. Para o monitoramento da IRFA, foi utilizado o aparelho analisador PAR-LAI modelo AccuPAR LP-80 da Decagon Devices Inc.®. 


\section{CARACTERÍSTICAS ESTRUTURAIS E PRODUTIVAS}

Figura 03: Corte de uniformização do pasto a $10 \mathrm{~cm}$ acima do solo (A e B) e aplicação dos fertilizantes via lanço $(\mathrm{C})$

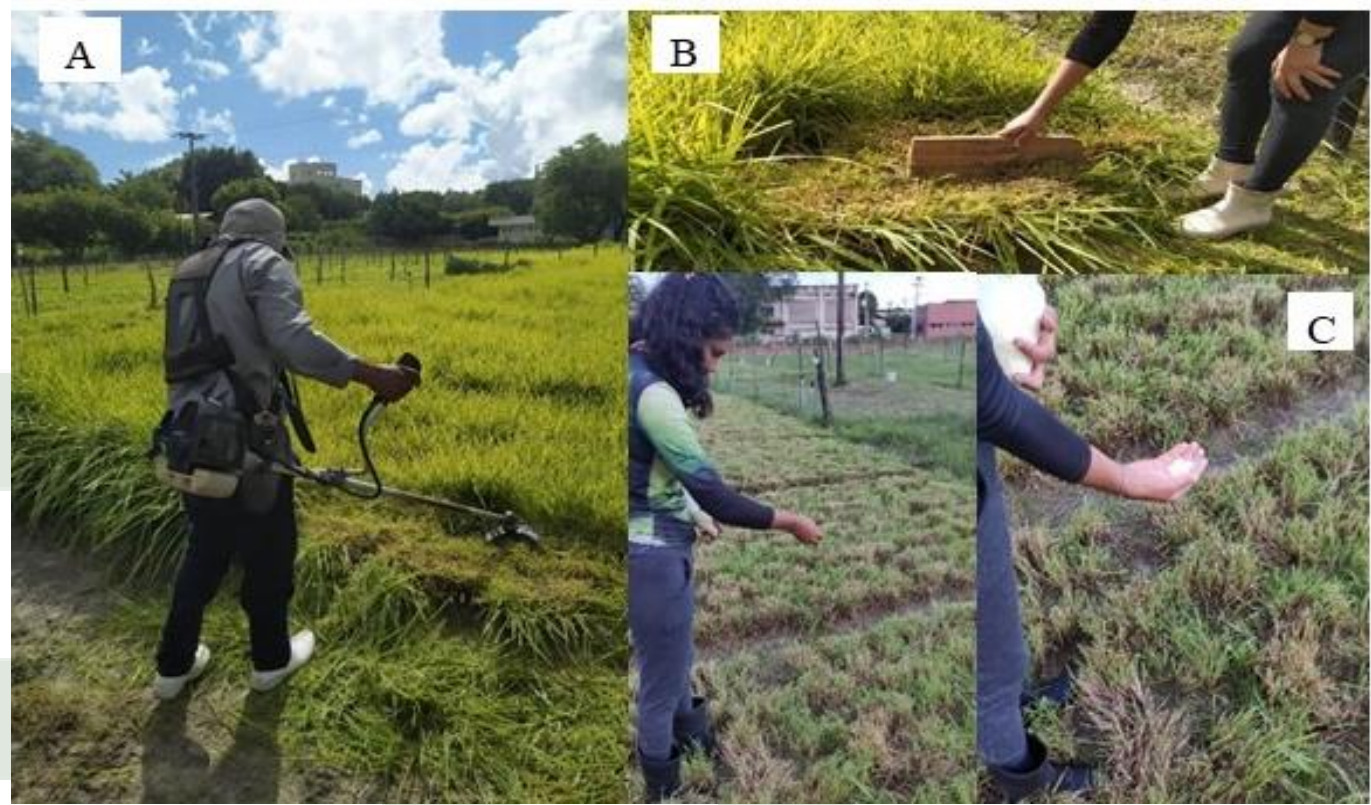

Fonte: Própria (2020)

As avaliações de interceptação luminosa foram realizadas entre as 11:00 e 13:00 horas (horário de maior intensidade de radiação solar). Foram realizadas leituras em dois pontos de amostragem por unidade experimental na condição de pré-desfolhação e dois pontos na condição residual. Em cada ponto de amostragem foram realizadas quatro leituras, sendo uma leitura acima da superfície do dossel e outra abaixo, próxima ao nível do solo (Figura 04 A).

A altura do dossel (AD) foi determinada medindo-se 20 pontos em cada parcela experimental, utilizando-se um bastão graduado retrátil (Figura 04 B).

A densidade populacional de perfilhos (DPP), foi estimada contando-se os perfilhos vivos dentro de uma moldura de 0,25 x $0,25 \mathrm{~m}$, em duas amostras dentro da unidade experimental (Figura $04 \mathrm{C}$ ).

Figura 04: Monitoramento da IRFA (A) e avaliações das características estruturais do dossel (B e C)

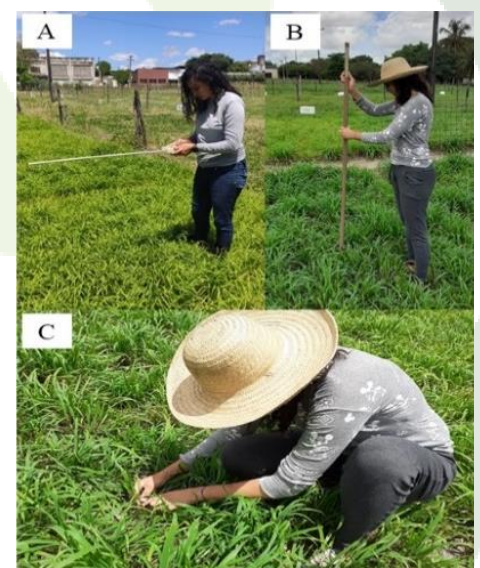

Fonte: Própria (2020) 
As biomassas de forragem total colhível $\left(\mathrm{BFT}_{\mathrm{C}}\right)$, de forragem morta colhível $\left(\mathrm{BFM}_{\mathrm{C}}\right)$, de forragem verde colhível $\left(\mathrm{BFV}_{\mathrm{C}}\right)$, de lâmina foliar verde colhível $\left(B L V_{C}\right)$, de colmo verde colhível $\left(\mathrm{BCV}_{\mathrm{C}}\right)$, foram estimadas cortando-se, em cada unidade experimental, duas amostras de 0,50 x 0,50 m a uma altura de $16 \mathrm{~cm}$ acima da superfície do solo (Figura 05 A). Após coleta as amostras foram levadas ao laboratório para separar o material vivo do morto, e em seguida separado as frações de lâminas dos colmos (Figura 05 B). Todas essas frações foram pesadas, secas em estufa de ventilação forçada a $55^{\circ} \mathrm{C}$ até atingir peso constante e pesadas novamente. A partir do peso seco total e das frações foram quantificadas as biomassas de forragem colhível.

Figura 05: Corte da biomassa colhível a $16 \mathrm{~cm}$ da superfície do solo (A) e fracionamento da biomassa colhível em fração folha, colmo e material morto (B)

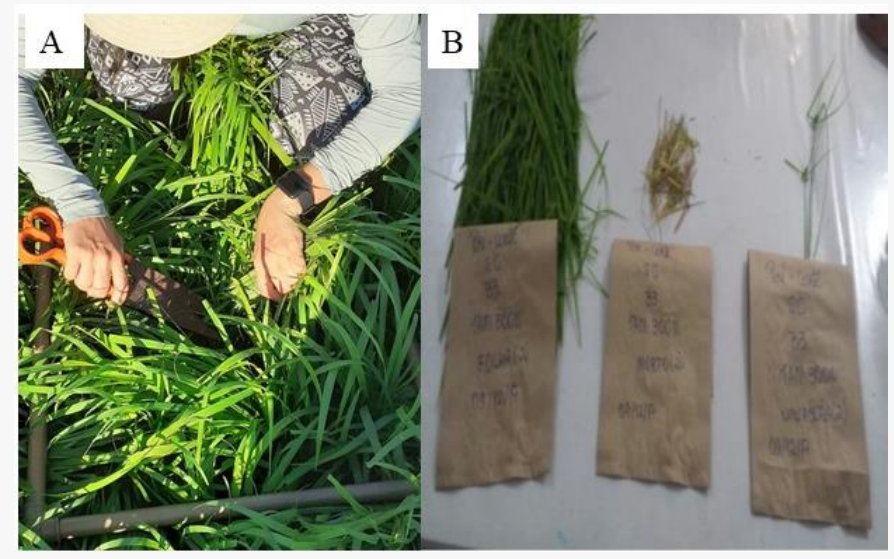

Fonte: Própria (2020) e Vasconcelos (2018)

Os dados foram submetidos à análise de variância e teste comparação de médias. As médias foram comparadas pelo teste de Tukey, ao nível de 5\% de probabilidade. Como ferramenta de auxílio a análise estatística foi utilizado o procedimento GLM, do programa computacional SAS (SAS INSTITUTE, 2003).

\section{RESULTADOS E DISCUSSÃO}

Observou-se que as características estruturais: altura do dossel (AD) e densidade populacional de perfilhos (DPP), e os componentes da biomassa de colmo verde colhível $(\mathrm{BCVc})$ e de forragem morta colhível $(\mathrm{BFMc})$, não responderam $(\mathrm{P}>0,05)$ aos tratamentos (Tabela 02). A DPP não sofreu efeito dos tratamentos mostrando mais um ponto positivo para o manejo de intensidade e frequência de desfolhação, pois não comprometeu a dinâmica de perfilhamento da comunidade vegetal, mesmo na ausência de adubação nitrogenada durante o período avaliado. 
CARACTERÍSTICAS ESTRUTURAIS E PRODUTIVAS

Tabela 02 - Médias das características estruturais e componentes da biomassa do capim tamani manejado sob parcelamentos da adubação nitrogenada

\begin{tabular}{ccccc}
\hline Tratamentos & \multicolumn{4}{c}{} \\
\cline { 2 - 5 } & AD $(\mathrm{cm})$ & DPP $\left(\right.$ perfilhos m$\left.{ }^{-2}\right)$ & ${\text { BCVc }\left(\mathrm{kg} \mathrm{ha}^{-1} \text { ciclo }\right)}$ & BFMc (kg ha ${ }^{-1}$ ciclo $)$ \\
\hline Ureia & $29,50 \mathrm{~A}$ & $1960,00 \mathrm{~A}$ & $0,45 \mathrm{~A}$ & $102,37 \mathrm{~A}$ \\
Polyblen 1x & $30,74 \mathrm{~A}$ & $2032,00 \mathrm{~A}$ & $0,45 \mathrm{~A}$ & $441,19 \mathrm{~A}$ \\
Polyblen 2x & $30,89 \mathrm{~A}$ & $2364,00 \mathrm{~A}$ & $0,51 \mathrm{~A}$ & $414,47 \mathrm{~A}$ \\
Polyblen 4x & $31,41 \mathrm{~A}$ & $2236,00 \mathrm{~A}$ & $0,50 \mathrm{~A}$ & $352,63 \mathrm{~A}$ \\
Polyblen 6x & $31,79 \mathrm{~A}$ & $2472,00 \mathrm{~A}$ & $0,48 \mathrm{~A}$ & $203,56 \mathrm{~A}$ \\
Sem nitrogênio & $32,50 \mathrm{~A}$ & $1944,00 \mathrm{~A}$ & $0,46 \mathrm{~A}$ & $79,62 \mathrm{~A}$ \\
\hline Média & 31,14 & 2168,00 & 0,47 & 264,51 \\
\hline CV (\%) & 8,89 & 12,09 & 6,76 & 58,07
\end{tabular}

$\mathrm{CV}=$ Coeficiênte de variação; Médias seguidas pela mesma letra na coluna, não diferem significativamente pelo teste de Tukey a 5\% de probabilidade. AD - Altura do dossel ( $\mathrm{cm}$ ); DPP - Densidade populacional de perfilhos (perfilhos $\mathrm{m}^{-2}$ ); BCVc - Biomassa de colmo verde colhível ( $\mathrm{kg} \mathrm{ha}^{-1}$ ciclo); BFMc - Biomassa de forragem morta colhível ( $\mathrm{kg} \mathrm{ha}^{-1}$ ciclo)

Fonte: Própria (2020)

No que diz respeito a biomassa de forragem total colhível (BFTc) (Figura 05 A), não houve diferença estatística entre os pastos que foram manejados com ureia convencional e aqueles manejados com ureia de liberação controlada. Entretanto, faz-se necessário ressaltar que, os pastos submetidos ao parcelamento da ureia de liberação controlada apresentaram em média, uma BFTc 40,78\% superior à dos pastos manejados com ureia convencional, destacando-se, dentre esses parcelamentos, o de 4 vezes ao ano (Poly 4x), que proporcionou uma biomassa de forragem total $44,11 \%$ maior que a observada no pasto adubado com ureia convencional. Esses resultados mostraram incrementos de 1012,16 kg. ha ${ }^{-1}$. ciclo $^{-1}$ para a fonte de ureia controlada com 6 aplicações. ano ${ }^{-1}$.

Tal resultado pode ser atribuído à maior eficiência da fonte proporcionada pela estrutura dos grânulos dos fertilizantes de liberação controlada. Estes, são revestidos por polímeros que absorverem água do solo, solubilizam os nutrientes no interior das cápsulas, liberando-os gradativamente pela estrutura porosa na zona da raiz, atendendo assim às necessidades das plantas, além disso, a maior quantidade de parcelamento reduz as perdas do nitrogênio e garante a sua disponibilidade no momento adequado para a utilização pela planta, durante o período de rebrotação (TOMASZEWSKA et al., 2002). 
Figura 06 - Médias da (A) - biomassa de forragem total colhível, (B) - biomassa de forragem verde colhível e (C) - biomassa de lâmina foliar verde colhível do capim tamani manejado sob parcelamentos da adubação nitrogenada
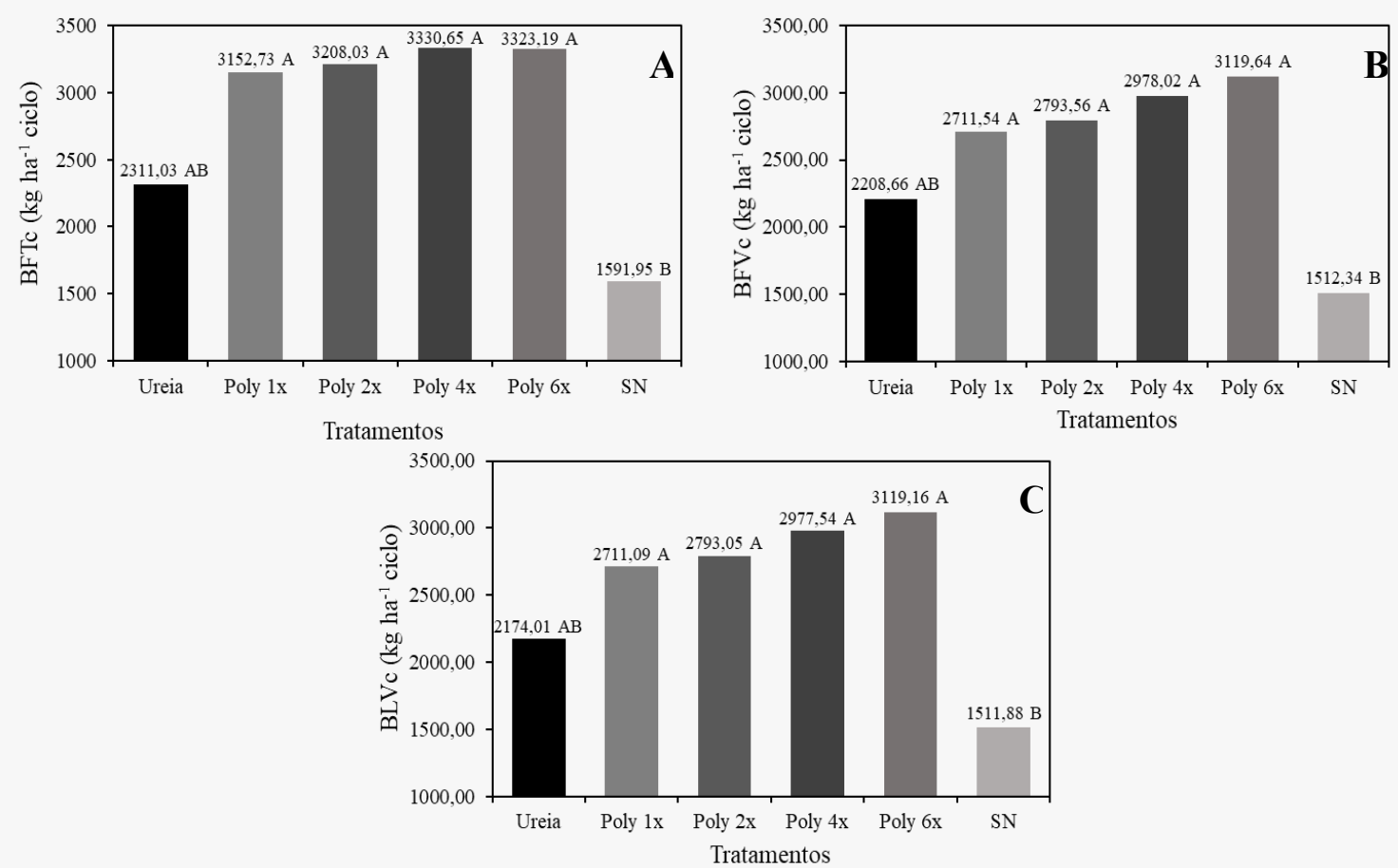

Fonte: Própria (2020)

Para a variável biomassa de forragem verde colhível (BFVc) (Figura 01 B), constatouse a ausência de diferença estatística entre os pastos submetidos a ureia convencional e a de liberação controlada, apesar da biomassa de forragem verde ter sido em média, 31,32\% maior nos pastos manejados com parcelamento da ureia de liberação controlada, com destaque para o parcelamento de 6 vezes ao ano (Poly 6x), que proporcionou uma biomassa de forragem verde $41,24 \%$ maior que a observada no pasto adubado com ureia convencional.

A produção de forragem é fortemente influenciada pela adubação, sobretudo pela nitrogenada, que modifica os processos de crescimento das plantas. Logo, a disponibilização deste macronutriente é uma das formas de incrementar a produtividade dos pastos, principalmente quando a forrageira considerada responde eficientemente a sua aplicação, como é o caso das cultivares de Megathyrsus maximus (MARTUSCELLO et al., 2015; MARTUSCELLO et al., 2009).

A maior produtividade observada nos pastos submetidos a ureia de liberação controlada, possivelmente está relacionada a menor volatilização da amônia $\left(\mathrm{NH}_{3}\right)$, assim como foi demonstrado por Chagas et al. (2017) que ao avaliarem a volatilização da citada substância em uma pastagem submetida a diferentes fontes nitrogenadas constataram que a ureia convencional apresentou uma taxa de volatilização 53,55\% maior que a volatilização apresentada pela ureia 


\section{CARACTERÍSTICAS ESTRUTURAIS E PRODUTIVAS}

de liberação controlada.

Hipotetiza-se que devido a essa maior volatilização, houve uma menor disponibilidade de nitrogênio para as plantas manejadas com ureia convencional. Essa disponibilidade reduzida, possivelmente não atendeu as necessidades de demanda do pasto para o seu desenvolvimento potencial máximo, afetando negativamente por consequência, a biomassa de forragem total colhível (BFTc) e a biomassa de forragem verde colhível (BFVc), respectivamente (YANG et al., 2011). Outro aspecto a se destacar é que o aumento no número de parcelamentos, teoricamente favorece a marcha de absorção do $\mathrm{N}$ pelo pasto, permitindo que as plantas absorvam o nutriente na época de maior necessidade (MARSCHNER, 1995), favorecendo assim, sua produtividade.

No tocante a biomassa de lâmina foliar verde colhível (BLVc), percebe-se, de forma semelhante as variáveis anteriores, que não houve diferença estatística entre os pastos que foram manejados com ureia convencional e aqueles manejados com ureia de liberação controlada, apesar da produtividade da variável em questão ter sido em média, 33,40\% superior nos pastos submetidos ao parcelamento da ureia de liberação controlada, com destaque para o parcelamento de 6 vezes ao ano (Poly 6x), que proporcionou uma BLVc 43,47\% superior a encontrada no pasto manejado com ureia convencional (Figura $05 \mathrm{C}$ ).

A maior BLVc observada para os pastos submetidos a ureia de liberação controlada possivelmente está relacionada a maior deposição de nitrogênio nas zonas de alongamento e divisão celular das folhas dos referidos pastos (SKINNER; NELSON, 1995), aliado a um provável maior estímulo ao desenvolvimento de primórdios foliares além do possível aumento do número de folhas vivas por perfilho (SILVEIRA; MONTEIRO, 2007).

A variável em questão é diretamente ligada a processos morfogênicos como a taxa de alongamento foliar que, segundo Braz et al. (2017) é a medida que apresenta maior grau de associação com o acúmulo de forragem e consequentemente, com o rendimento forrageiro. Martuscello et al. (2019) complementam afirmando que a produção de biomassa de lâmina foliar é uma característica importante para o crescimento das forrageiras, uma vez que a lâmina é o componente fotossinteticamente mais ativo e capaz de promover incrementos na taxa de crescimento de plantas forrageiras e no acúmulo de forragem.

Lopes et al. (2013), Martuscello et al. (2015) e Martuscello et al. (2019) obtiveram resposta linear crescente para a produção de biomassa total e biomassa de lâminas foliares, respetivamente com o aumento da disponibilidade de $\mathrm{N}$, proporcionado pelo incremento na adubação nitrogenada. Em paralelo a isso, no presente trabalho, apesar da dose utilizada ter sido a mesma para todos os tratamentos, observa-se claramente, uma tendência de maior 
desenvolvimento dos pastos adubados com ureia de liberação controlada, destacando-se aqueles submetidos ao maior número de parcelamentos.

A partir desses resultados infere-se que a utilização de adubos de liberação controlada apresenta-se como estratégia para a redução na utilização de adubos nitrogenados convencionais, aliando-se a essa redução, a manutenção na produtividade do pasto. Vale ressaltar que esse fato vai totalmente de encontro com questões relacionadas a sustentabilidade das propriedades, principalmente as mais intensificadas, demonstrando que existe a possibilidade de se obter produtividade e, ao mesmo tempo, conservar os recursos ambientais.

\section{CONCLUSÕES}

A aplicação do adubo nitrogenado comercial de liberação controlada não influenciou as características estruturais da pastagem de Megathyrsus maximus cv. Tamani.

Os tratamentos com adubo nitrogenado comercial de liberação controlada, independentemente do parcelamento adotado, proporcionaram maior produtividade da gramínea BRS Tamani durante o período avaliado.

\section{REFERÊNCIAS}

ALEXANDRINO, E.; NASCIMENTO JÚNIOR, D.; MOSQUIM, P. R.; REGAZZI, A. J.; ROCHA, F. C. Características morfogênicas e estruturais na rebrotação da Brachiaria brizantha cv. Marandu submetida a três doses de nitrogênio. Revista Brasileira de Zootecnia, v. 33, p. 1372-1379, 2004.

ANDRADE, A. C.; FONSECA, D. M.; GOMIDE, J. A.; ALVAREZ, V. H.; MARTINS, C. E.; SOUZA, D. P. H. Produtividade e valor nutritivo do capim elefante cv. napier sob doses crescentes de nitrogênio e potássio. Revista Brasileira de Zootecnia, v. 29, p. 1589-1595, 2000 .

BRAZ, T. G. S.; MARTUSCELlO, J. A.; SANTOS, M. E. R.; PEREIRA, V.V. Partial correlation analysis in the study of morphogenesis and herbage accumulation in Panicum maximum cv.'Tanzânia'. Ciência Rural, v. 47, n. 9, p. 1-4, 2017.

BREDEMEIER, C.; MUNDSTOCK, C. M. Regulação da absorção e assimilação do nitrogênio nas plantas. Ciência Rural, v. 30, n. 2, p. 365-372, 2000.

CÂNDIDO, M. J. D. Morfofisiologia e crescimento do dossel e desempenho animal em Panicum maximum cv. Mombaça sob lotação intermitente com três períodos de descanso. Viçosa: UFV, 2003. 134 f. 2003. Tese (Doutorado em Zootecnia) - Universidade Federal de Viçosa, 2003.

CARVALHO, P. C. F.; RIBEIRO FILHO, H. M. N.; POLI, C. H. E. C.; MORAES, A.; DELAGARDE, R. A importância da estrutura da pastagem na seleção de dietas pelo animal em pastejo. In: SIMPÓSIO SOBRE A PRODUÇÃO ANIMAL NA VISÃO DOS BRASILEIROS/ 
REUNIÃO DA SOCIEDADE BRASILEIRA DE ZOOTECNIA, 38, 2001, Piracicaba. Anais... MATTOS, W. R. S. et al. (Ed.). Piracicaba: FEALQ, 2001. p. 853-871.

Comissão de Fertilidade do Solo do Estado de Minas Gerais - CFSEMG, 1999. Recomendações para uso de corretivos e fertilizantes em Minas Gerais - $5^{\text {a }}$ Aproximação - Viçosa: UFV, 1999, 359 p.

CHAGAS, P. H. M.; GOUVEIA, G. C. C.; COSTA, G. G. S.; BARBOSA, W. F. S.; ALVES, A. C. Volatilização de amônia em pastagem adubada com fontes nitrogenadas. Revista de Agricultura Neotropical, v. 4, n. 2, p. 76-80, 2017.

CREWS, T.E.; PEOPLES, M.B. Can the synchrony of nitrogen supply and crop demand $b$ improved in legume and fertilizer based agroecosystems? A review. Nutrient Cycling Agroecosystem, v. 72, p. 101-120, 2005.

EDMEADES, D. C. The evaluation of a controlled release nitrogen fertiliser. Journal of New Zealand Grasslands, v. 77, p. 147-152, 2015.

HARPER, J.E. Nitrogen metabolism. In: BOOTE, K.J., BENNETT. J.M., SINCLAIR, T.R., et al. Physiology and determination of crop yield. Madison: ASA/CSSA/SSSA, 1994. Chapt.11A. p.285-302.

HODGSON, J. Grazing management: science into practice. Harlow: Longman Scientific \& Technical, 1990. $203 \mathrm{p}$.

JUNG, H. G.; ALLEN, M. S. Characteristics of plant cell walls affecting intake and digestibility of forages by ruminants. Journal of Animal Science, v. 73, p. 2774-2790, 1995.

KIEHL, J.C. Distribuição e retenção da amônia no solo após aplicação de uréia. Revista Revista Brasileira de Ciência do Solo, Viçosa, v. 13, p. 75-80, 1989.

KLUTHCOUSKI, J.; AIDAR, H. 2003. Uso da integração lavoura-pecuária na recuperação de pastagens. p.185-223. In: Integração lavoura-pecuária. Santo Antônio de Goiás: Embrapa Arroz e Feijão.

KÖPPEN, W. P. Die Klimate der Erde: Grundriss der Klimakunde. Walter de Gruyter \& Company, 1923.

LACA, E. A.; LEMAIRE, G. Measuring sward structure. In: t'MANNETJE, L.; JONES, R. M. (Ed.). Field and laboratory methods for grassland and animal production research. Wallinford: CAB International, 2000. p. 103-122.

LAM, S. K.; SUTER, H.; BAI, M.; WALKER, C.; MOSIER, A. R.; VAN GRINSVEN, H.; CHEN, D. Decreasing ammonia loss from an Australian pasture with the use of enhanced efficiency fertilizers. Agriculture, Ecosystems \& Environment, v. 283, p. 106553, 2019.

LEMAIRE, G. Ecophysiology of grasslands: dynamics aspects of plant population in grazed swards. In: INTERNATIONAL GRASSLAND CONGRESS, 19, 2001, São Pedro. Proceedings... (CD-ROM). 
LEMAIRE, G.; CHAPMAN, D. F. Tissue flows in grazed plants communities. In: HODGSON, J., ILLIUS, A W. (Ed.). The ecology and management of grazing systems. Wallingford: CAB International, 1996. p. 3-36.

LOPES, M. N.; CÂNDIDO, M. J. D.; POMPEU, R. C. F. F.; SILVA, R. G.; LOPES, J. W. B.; FERNANDES, F. R. B.; LACERDA, C. F.; BEZERRA, F. M. L. Fluxo de biomassa em capimmassai durante o estabelecimento e rebrotação com e sem adubação nitrogenada. Revista Ceres, v. 60, n. 3, p. 363-371, 2013.

MARSCHNER, H. Functions of Mineral Nutrients: Micronutrients. Academic Press, London, 2nd Edition, p. 313-404. 1995.

MARTHA JUNIOR, G. B.; CORSI, M.; TRIVELIN, P. C. O.; VILELA, L. PINTO, T. L. F.; TEIXEIRA, G. M.; MANZONI, C. S.; BARIONI, L. G. Perda de amônia por volatilização em pastagem de capim-tanzânia adubada com uréia no verão. Revista Brasileira de Zootecnia, v. 33, n. 6, p. 2240-2247, 2004.

MARTUSCELlO, J. A.; RIOS, J. F.; FERREIRA, M. R.; ASSIS, J. A.; BRAZ, T. G. S.; CUNHA, D. N. F. V. Produção e morfogênese de capim BRS Tamani sob diferentes doses de nitrogênio e intensidades de desfolhação. Boletim de Indústria Animal, v. 76, p. 1-10, 2019.

MARTUSCELLO, J. A.; SILVA, L. P.; CUNHA, D. N. F. V.; BATISTA, A. C. S.; BRAZ, T. G. S.; FERREIRA, P. S. Adubação nitrogenada em capim-massai: morfogênese e produção. Ciência Animal Brasileira, v.16, p. 1-13, 2015.

MARTUSCELLO, J. A; JANK, J.; GONTIJO NETO, M. M.; LAURA, V. A.; CUNHA, D. N. F. V. Produção de gramíneas do gênero Brachiaria sob níveis de sombreamento. Revista Brasileira de Zootecnia, v.38, p.1183-1190, 2009.

MIFLIN, B.J., LEA, P.J. The pathway of nitrogen assimilation in plants. Phytochemistry, New York, v.15, p.873-885, 1976.

MINSON, D. J. Forage in Ruminant Nutrition. London: Academia Press, 1990. 483 p.

NABINGER. C.; PONTES, L. S. Morfogênese de plantas forrageiras e estrutura do pasto. In: SIMPÓSIO SOBRE A PRODUÇÃO ANIMAL NA VISÃO DOS BRASILEIROS/ REUNIÃO DA SOCIEDADE BRASILEIRA DE ZOOTECNIA, 38, 2001, Piracicaba. Anais... MATTOS, W. R. S. et al. (Ed.). Piracicaba: FEALQ, 2001. p. 755-771.

PAN, B.; LAM, S. K.; MOSTER, A.; LUO, Y.; CHEN, D. Ammonia volatilization from synthetic fertilizers and its mitigation strategies: a global synthesis. Agriculture, Ecosystems \& Environment, v. 232, p. 283-289, 2016.

PINTO, J. C.; GOMIDE, J. A.; MAESTRI, M. Produção de matéria seca e relação folha:caule de gramíneas forrageiras tropicais, cultivadas em vasos, com duas doses de nitrogênio. Revista da Sociedade Brasileira de Zootecnia, v. 23, n. 3, p. 313-326, 1994.

PRADO, R. M. Manual de Nutrição de Plantas Forrageiras. Editora Funep, 500p. 2008. SANTOS, P. M. Aspectos fisiológicos e metabólicos da nutrição nitrogenada de plantas forrageiras. In: SIMPÓSIO SOBRE MANEJO DA PASTAGEM, 21, 2004, Piracicaba. 
Anais... PEDREIRA, C. G. S.; MOURA, J. C.; FARIA, V. P. (Ed.). Piracicaba: FEALQ, 2004, p. $139-152$.

SHAVIV, A. Controlled release fertilizers. In: INTERNATIONAL WORKSHOP ON ENHANCED EFFICIENCY FERTILIZERS, 2005, Frankfurt. Proceedings... Frankfurt: International Fertilizer Industry Association, 2005. p. 1-13.

SILVA, C. C. F.; BONOMO, P.; PIRES, A. J. V.; MARANHÃO, C. M. A.; PATÊS, N. M. S.; SANTOS, L. C. Características morfogênicas e estruturais de duas espécies de braquiária adubadas com diferentes doses de nitrogênio. Revista Brasileira de Zootecnia, v. 38, p. 657661, 2009.

SILVEIRA, C. P.; MONTEIRO, F. A. Morfogênese e produção de biomassa do capim-tanzânia adubado com nitrogênio e cálcio. Revista Brasileira de Zootecnia, v. 36, n. 2, p. 335-342, 2007.

SKINNER, R. H.; NELSON, C. J. Elongation of the grass leaf and its relationship to the phyllochron. Crop Science, v. 35, n. 1, p. 4-10, 1995.

STOBBS, T. H. The effect of plant structure on the intake of tropical pastures. II. Differences in swards structure, nutritive value, and bite size of animal grazing Setaria anceps and Cloris gayana at various stages of growth. Australian Journal and Agriculture Resource, v. 24, n. 6, p. 821-829, 1973.

TOMASZEWSKA, M.; JARPSOEWICZ, A.; KARAKKULSKI, K. Physical and chemical characteristics of polymer coatings in CRF formulation. Desalination, v. 146, n. 03, p. 319$323,2002$.

VASCONCELOS, E. C. G. Morfofisiologia do capim-Tamani irrigado sob doses de nitrogênio. 2018. 63f. Tese (Doutorado em Zootecnia) - Universidade Federal do Ceará, Fortaleza, 2018.

VILLALBA, H. A. G. Misturas de ureia revestida com polímeros e ureia convencional na adubação da cultura de milho. 2014. 91f. Dissertação (Mestrado) - Escola Superior de Agricultura "Luiz de Queiroz", Piracicaba, 2014.

XIA, L.; LAM, S. K.; CHEN, D.; WANG, J.; TANG, Q.; YAN, X. Can knowledge-based N management produce more staple grain with lower greenhouse gas emission and reactive nitrogen pollution? A meta-analysis. Global Change Biology, v. 23, p. 1917-1925, 2017.

YANG, Y. C.; ZHANG, M.; ZHENG, L.; CHENG, D. D.; LIU, M.; GENG, Y. Q. Controlled release urea improved nitrogen use efficiency, yield, and quality of wheat. Agronomy Journal, v. 103, n. 2, p. 479-485, 2011. 